\title{
Cyto-histo correlation of conventional Pap smear with cervical biopsy in diagnosis of precancerous and cancerous lesions of cervix
}

\author{
Farha Jalaly Meenai ${ }^{1}$, Shabana Andleeb Ansari ${ }^{2, *}$, Sonam Gupta ${ }^{3}$, Manal Ashraf $\mathrm{Ali}^{4}$ \\ ${ }^{\mathbf{1}}$ Associate Professor, ${ }^{\mathbf{2 , 4}}$ Assistant Professor, ${ }^{3}$ Tutor, Dept. of Pathology, Chirayu Medical College and Hospital, Bhopal, Madhya \\ Pradesh, India \\ *Corresponding Author: \\ Email: dr.shaazm@gmail.com
}

\begin{abstract}
Introduction: Carcinoma of uterine cervix is the third most common cancer among women worldwide and it contributes significantly to cancer related morbidity and mortality. The incidence of cervical carcinoma is incredibly high in developing countries (almost 80\%) due to lack of proper knowledge. The extensive use of cervical screening with Pap smears has considerably increased the detection of precancerous and cancerous lesions of uterine cervix.

Aims: To evaluate cyto-histo correlation of precancerous and cancerous lesions of uterine cervix and to calculate the sensitivity and specificity of Pap smear in diagnosing invasive malignancy.

Materials and Methods: This was a retrospective observational study conducted in the Department of Pathology, Chirayu Medical College \& Hospital, Bhopal from January 2013 to April 2018. All the cases reported in Pap smear as cervical intraepithelial lesions and invasive malignancies were retrieved. We also retrieved the same cases, if they had undegone cervical biopsy for correlation. Result: During the study period total 303 cases which were positive for intraepithelial lesions and malignancies were retrieved. Out of these 303 cases we excluded 23 cases because in these cases cervical biopsy had not been done. So in the final analysis 280 cases were included. Of the 280 Pap smears, maximum cases (33.92\%) were reported as low grade squamous intraepithelial lesion (LSIL), followed by high grade squamous intraepithelial lesion (HSIL) (24.28\%), atypical squamous cells of undetermined significance (ASCUS) (19.64\%), atypical squamous cells - cannot rule out HSIL (ASC-H) (10\%). We had 23 cases of invasive malignancy which includes 21 cases of squamous cell carcinoma (SCC) and 2 cases of adenocarcinoma. There were 11 cases of atypical glandular cells of undetermined significance (AGUS). We found that total numbers of concordant cases were $68.57 \%$ $(192 / 280)$ and discordant cases were $31.43 \%$ (88/280). We also found that sensitivity and specificity of cervical smear in diagnosing invasive malignancy were $61.76 \%$ and $99.1 \%$ respectively considering cervical biopsy as gold standard.

Conclusion: The study revealed a good correlation between cervical cytology and cervical biopsy. We also concluded that conventional Pap smear is cost effective test for the early detection of precancerous and cancerous cervical lesions.
\end{abstract}

Keywords: Conventional Pap smear, Cervical biopsy, Cervical intraepithelial lesions (CIN), Low grade squamous intraepithelial lesion (LSIL), High grade squamous intraepithelial lesion (HSIL).

\section{Introduction}

Carcinoma of uterine cervix is the third most common cancer among women worldwide ${ }^{1}$ and it contributes significantly to cancer related morbidity and mortality. ${ }^{2}$ The incidence of cervical carcinoma is incredibly high in developing countries (almost 80\%) due to lack of proper knowledge and long intervals between tests and non-existent preventive programmes. ${ }^{1}$

The risk factors for cervical cancer are related to both host and viral characteristics such as human papilloma virus exposure, viral oncogenicity, inefficiency of immune response and presence of cocarcinogens. Prospective studies have demonstrated that infection with high risk HPV types consistently precedes the development of CIN II/III.-7 These studies are further supported by molecular studies identifying the mechanisms by which high risk HPV types contribute to carcinogenesis. ${ }^{4,5}$

In 1988, the US National Cancer Institute convened a workshop to propose a new scheme for reporting cervical cytology results. ${ }^{8-10}$ The recommendations from this workshop and the subsequent revision in a second workshop held in 1991 became known as the Bethesda system. ${ }^{8}$ The main feature of Bethesda system was the creation of the term squamous intraepithelial lesion (SIL), and a two-grade scheme consisting of low grade (LSIL) and high-grade (HSIL) lesions.

Table 1: Classification of cervical precancerous lesions ${ }^{11}$

\begin{tabular}{|l|c|c|}
\hline Dysplasia/Carcinoma in situ & $\begin{array}{c}\text { Cervical Intraepithelial } \\
\text { Neoplasia (CIN) }\end{array}$ & $\begin{array}{c}\text { Squamous intraepithelil lesion } \\
\text { (SIL) }\end{array}$ \\
\hline Mild dysplasia & CIN I & Low grade SIL (LSIL) \\
\hline Moderate dysplasia & CIN II & High grade SIL (HSIL) \\
\hline Severe dysplasia & CIN III & High grade SIL (HSIL) \\
\hline Carcinoma in situ & CIN III & High grade SIL (HSIL) \\
\hline
\end{tabular}


Natural History of Cervical Intraepithelial Neoplasia (CIN): The natural history of cervical intraepithelial lesions is extremely variable. Untreated cervical intraepithelial lesions may either return to normal or progress to invasive cervical cancers. About $60 \%$ of low grade squamous intraepithelial lesions (LSIL) can regress. ${ }^{12}$ LSIL persists in $30 \%$ of patients while $10 \%$ progress to high grade squamous intraepithelial lesions (HSIL). About $30 \%$ of high grade squamous intraepithelial lesions can regress while it persists in $60 \%$ of patients and $10 \%$ progress to carcinoma. ${ }^{3}$ The time for CIN III to progress to invasive cancer has been reported as ranging from 1 to 30 years, although it is now accepted that abnormalities detected by screening only develop into invasive cervical cancer if high risk subtypes of HPV persist over a number of years. ${ }^{4,13}$

One of the earliest major advances in cervical cancer screening was the Papanicolaou (Pap) test. George N. Papanicolaou, a zoologist by training, developed a microscopic technique to examine vaginal debris in guinea pigs. The technique, which he extended to human volunteers, led to a chance discovery of malignant cells. Thus he recognized its potential to detect cervical cancer in humans through examination of cervical scrapings. ${ }^{14,15}$

The extensive use of cervical screening with Conventional Pap smears has considerably increased the detection of precancerous and cancerous lesions of uterine cervix in developed countries. ${ }^{16}$ It has also been noted that most cervical abnormality can be diagnosed at the preinvasive and treat stage with adequate and repetitive cervical cytological screening. ${ }^{1,17}$ Cervical biopsy was generally done after an abnormality has been detected during pelvic examination or Conventional smear. Cyto-Histo correlation of cervical smear is a best way of internal quality assurance and also sometimes help to find out the factors responsible for discrepent cases. $^{1,18}$

\section{Aim}

The aim of this study was to evaluate cyto-histo correlation of precancerous and cancerous lesions of uterine cervix and to calculate the sensitivity and specificity of conventional Pap smear in diagnosing invasive malignancy.

\section{Materials and Methods}

Setting: This study titled "Cyto-Histo correlation of conventional Pap smear with cervical biopsy in diagnosis of precancerous and cancerous lesions of cervix" was a retrospective observational study conducted in the Department of Pathology, Chirayu Medical College \& Hospital, Bhopal which is a tertiary care chariT hospital. This study was carried out from January 2013 to April 2018.

\section{Study Material}

Cases: All the cases $(n=303)$ reported in Conventional Pap smear according to Bathesda system as cervical intraepithelial lesions and invasive malignancies were retrieved from hospital medical record and Lab Information System (LIS) and selected as study cases. Then we also retrieved the same cases, if they had undegone cervical biopsy for correlation. The duration between conventional Pap smear and cervical biopsy was approximately 1 week to 1 month. Out of these 303 cases we excluded 23 cases because in these cases cervical biopsy had not been done. So in the final analysis 280 cases were included.

Exclusion Criteria: Cases which were reported as Negative for intraepithelial lesion or malignancy (NILM) and those cases which did not undergo cervical biopsy were excluded from the study.

Method of Conventional Pap Smear and Cervical Biopsy: Conventional Pap smears were taken by the gynaecologists at the squamocolumnar junction using endocervical brush. Two slides were prepared, fixed in 95\% ethyle alcohol and stained with Pap stain. Cervical biopsy was taken in cases of epithelial abnormalities, fixed in $10 \%$ formalin, routinely processed and stained with haematoxylene and eosin.

Reporting: All the Pap smears were reported according to "The Bethesda System (2001 TBS)"8 and cervical biopsy were reported according to "WHO classification of tumours of uterine cervix". ${ }^{1}$ The cytological findings were correlated with histopathological findings. We also calculated the sensitivity and specificity of conventional Pap smear in diagnosing invasive malignancy.

\section{Results}

Table 1 shows the distribution of cases according to the ages of the study participants. These 280 study cases were retrieved from women aged 21-80 years (Mean = 50.5). Of these, 92 samples (32.8\%) belonged to women in the age group of 41-50 years. The samples from women in the age group of 31-40 years (29.6\%) and 5170 years $(27 \%)$ were almost equal. We also had 9 cases of women aging $>70$ years.

Table 2 shows the distribution of cases according to their Pap smear diagnoses. Of the 280 Pap smears, maximum cases $(33.92 \%)$ were reported as low grade squamous intraepithelial lesion (LSIL), followed by high grade squamous intraepithelial lesion (HSIL) (24.28\%), atypical squamous cells of undetermined significance (ASCUS) (19.64\%), atypical squamous cells - cannot rule out HSIL (ASC-H) (10\%). We had 23 cases of invasive malignancy which includes 21 cases of squamous cell carcinoma (SCC) and 2 cases of adenocarcinoma. There were 11 cases of Atypical glandular cells of undetermined significance (AGUS) in which reporting was difficult to differentiate between reactive changes or neoplastic etiology and hence biopsy was mandatory to differentiate between the two. 
Table 3 shows the distribution of cases according to their cervical biopsy diagnoses. When we retrieved the cases that had undergone cervical biopsy, we found that maximum cases belonged to CIN I category $(86 / 280)$. We excluded the NILM cases but we still found 49 cases of chronic cervicitis, single case of chronic cervicitis with squamous metaplasia, 6 cases of papillary endocervicitis. The number of CIN II (47/280) and CIN III $(49 / 280)$ were almost equal. We had 08 cases of carcinoma in situ in which tumour is restricted to the basement membrane. In invasive malignancy we had 26 cases of squamous cell carcinoma and 08 cases of adenocarcinoma.

Table 4 shows the detailed correlation of diagnoses made on Pap smears and cervical biopsy. When we correlated the Pap smears and cervical biopsies, we found that 55 cases belonging to ASCUS category reported on cervical cytology were diagnosed as CIN I (27 cases), 24 cases were downgraded as chronic cervicitis and 04 cases were upgraded as CIN II on cervical biopsy. There were 11 cases of AGUS, of these 05 cases were upgraded as adenocarcinoma while 06 cases were diagnosed as papillary endocervicitis. Of the 95 cases of LSIL, 58 cases correlated with histopathology diagnosis as CIN I, 11 cases were upgraded as CIN II, 25 cases were downgraded as chronic cervicitis and single case of chronic cervicitis with squamous metaplasia.

We had 68 cases of HSIL, 60 cases matched the diagnosis of moderate to severe dysplasia (CIN II \& CIN III) while 06 cases were upgraded as CIS (02 cases), SCC ( 05 cases) and adenocracinoma (01 case). When we compared the ASC-H group, we found that 21 cases belonged to CIN II and CIN III, 04 cases of CIS, 02 cases of SCC and single case was downgraded as CIN I. We also had 23 cases of invasive malignancy which includes 02 cases of adenocarcinoma reported on both Pap smear and cervical biopsy. Out of 21 cases of SCC reported on Pap smear, 02 cases did not show proper invasion on cervical biopsy so we classified these cases as carcinoma in situ.

$\mathrm{T} 5$ shows that there were good concordance in HSIL (88.23\%) cases and ASC-H (75\%) cases. In cases of SCC the concordance was $90.47 \%$ while in cases of adenocarcinoma it was $100 \%$. We also found that concordance in cases of ASCUS, AGUS and LSIL were about $50-60 \%$. So total numbers of concordant cases were $68.57 \%(192 / 280)$ and discordant cases were $31.43 \%$ (88/280).

T 6 shows that 04 cases reported as ASCUS on cervical cytology were turned out CIN II on cervical biopsy. Here is cytology occasional atypical cells were seen which could not confidently be classified to HSIL. We had 06 cases of AGUS which were reported as papillary endocervicitis, in these cases reporting was difficult to differentiate between reactive changes or neoplastic etiology, so it was a screening error. Another 11 cases reported as LSIL on Pap smear were finally diagnosed as CIN II on cervical biopsy, the reason is single cluster of atypical cells embedded in marked inflammatory infiltrates were seen in most cases. There were 08 cases initially reported as HSIL on cervical cytology were upgraded as squamous cell carcinoma and adenocarcinoma on cervical biopsy. These smears did not show enough tumour diathesis or other features to confidently label them malignancy. Six out of seven cases of ASC-H were upgraded on cervical biopsy as carcinoma in situ (04 cases) and SCC (02 cases) in which abundant inflammatory cells and necrosis seen in smears created problems in reporting. Also we had 02 cases of SCC which were downgraded as CIS. In these cases tadpole cells were not identified in cervical smears.

We also found that sensitivity and specificity of cervical smear in diagnosing invasive malignancy were $61.76 \%$ and $99.1 \%$ respectively considering cervical biopsy as gold standard.

\section{Discussion}

The cervix is both sentinel for potentially serious genital tract infections and a target for viruses, as well as other carcinogens which may lead to precancerous lesions and invasive carcinoma. ${ }^{19}$ Despite the decline in incidence of cervical cancer in developed countries in the past few decades, carcinoma of the uterine cervix remains the second most common cancer in women worldwide ${ }^{20,21}$ because of lack of proper knowledge, long intervals between tests and non-existent preventive programmes. ${ }^{1}$ The goal of cervical screening is early detection of cervical cancer and precursor lesions. ${ }^{22}$ Sankaranarayanan et $\mathrm{al}^{23}$ have stated that the incidence of cervical cancer can be reduced by as much as $80 \%$ if the quality, coverage, and follow-up of screening are high.

We included only precancerous and cancerous lesions, so our number and percentage of patients having these lesions were high while other studies showed maximum number of normal / chronic inflammatory cases. In our study invasive malignancy was found in $12 \%$ cases which are similar to studies conducted by Saha et $\mathrm{al}^{24}$ and Dhakal et al. ${ }^{18}$ The mean age of patients with cancer was 52.25 years in our study which is similar to the study of Bodal et $\mathrm{al}^{25}$ (51.94 years) and Dhakal et $\mathrm{al}^{18}$ (52.75 years).

Various studies mentioned the sensitivity and specificity of cytology for detecting cervical neoplasia that ranged from $50-98 \% .{ }^{26}$ There are different methods which were studied to improve the cervical screening but cervical biopsy has been considered as the gold standard for detecting cervical lesions. ${ }^{18,27}$ In the present study, sensitivity and specificity of cervical cytology in detecting cervical malignancy were $61.76 \%$ and $99.1 \%$ respectively while Dhakal et al ${ }^{18}$ and Chhabra et al ${ }^{28}$ had sensitivity of $77.8 \%$ and $81 \%$ respectively. Similarly specificity was comparable with studies done by Dhakal et $\mathrm{al}^{18}(100 \%)$ and Tamboli et $\mathrm{l}^{29}(90.3 \%)$. In this study 
we have compared the cytological findings with cervical biopsy in the lesions of cervix.

When we correlated the cyto-histo diagnoses, we found that out of 280 cases, $192(68.57 \%)$ were concordant while discrepencies occurred in $88(31.43 \%)$ cases. When we analysed these discrepent cases we found that ASCUS (04 cases) and LSIL (11 cases) were upgraded as CIN II. Amongst all the cytological diagnosed cases of HSIL, 60 cases correlated with histopathological diagnosis while 08 cases were upgraded as CIS (02 cases), SCC (05 cases) and single case of adenocarcinoma, While the study conducted by Dhakal et $\mathrm{al}^{18}$ showed that two out of seven cases of HSIL were upgraded as carcinoma. There were 07 discrepent cases in ASC-H category, 06 cases showed higher epithelial abnormality as CIS (04 cases) and SCC (02 cases) while single case was downgraded as CIN I. There were 21 cases which were diagnosed as SCC on cytology, 19 were correlated with histopathological diagnosis while 02 cases were reported on CIS. Also there were two true positive cases of adenocarcioma. In cytology the causes of discrepencies in diagnosis were screening error, presence of very few atypical cells, cluster of typical cells embedded in abundant inflammatory infiltrates, presence of necrosis and absence of tadpole cells. While Dhakal et $\mathrm{al}^{20}$ reported that the main reasons for false negative results in cytology in their study were inadequate sampling and technical error.

Table 1: Distribution of cases according to the ages of study participants

\begin{tabular}{|l|c|c|}
\hline $\begin{array}{c}\text { Age range } \\
\text { (in years) }\end{array}$ & No. of samples & $\begin{array}{c}\text { Percentage } \\
(\%)\end{array}$ \\
\hline Upto 30 & 20 & 7.1 \\
\hline $31-40$ & 83 & 29.6 \\
\hline $41-50$ & 92 & 32.8 \\
\hline $51-60$ & 47 & 16.7 \\
\hline $61-70$ & 29 & 10.3 \\
\hline$>70$ & 9 & 3.2 \\
\hline Total & 280 & 100 \\
\hline
\end{tabular}

Table 2: Distribution of cases according to their Pap smear diagnoses

\begin{tabular}{|l|c|c|}
\hline \multicolumn{1}{|c|}{ Diagnosis } & No. of cases & Percentage (\%) \\
\hline $\begin{array}{l}\text { Atypical squamous cells of undetermined significance } \\
\text { (ASCUS) }\end{array}$ & 55 & 19.64 \\
\hline Atypical glandular cells of undetermined significance (AGUS) & 11 & 3.92 \\
\hline Low grade squamous intraepithelial lesion (LSIL) & 95 & 33.92 \\
\hline High grade squamous intraepithelial lesion (HSIL) & 68 & 24.28 \\
\hline Atypical squamous cells - cannot rule out HSIL (ASC-H) & 28 & 10 \\
\hline Squamous cell carcinoma (SCC) & 21 & 7.5 \\
\hline Adenocarcinoma & 02 & 0.7 \\
\hline Total cases & 280 & 100 \\
\hline
\end{tabular}

Table 3: Distribution of cases according to their cervical biopsy diagnoses

\begin{tabular}{|l|c|c|}
\hline \multicolumn{1}{|c|}{ Diagnosis } & No. of cases & Percentage (\%) \\
\hline Chronic cervicitis & 49 & 17.5 \\
\hline Chronic cervicitis with squamous metaplasia & 1 & 0.35 \\
\hline Papillary endocervivitis & 6 & 2.14 \\
\hline Cervical intraepithelial neoplasia (CIN) I & 86 & 30.71 \\
\hline Cervical intraepithelial neoplasia (CIN) II & 47 & 16.78 \\
\hline Cervical intraepithelial neoplasia (CIN) III & 49 & 17.5 \\
\hline Carcinoma in situ & 8 & 2.85 \\
\hline Squamous cell carcinoma & 26 & 9.28 \\
\hline Adenocarcinoma & 8 & 2.85 \\
\hline Total cases & 280 & 100 \\
\hline
\end{tabular}

Table 4: Correlation of diagnoses made on Pap smears and cervical biopsy

\begin{tabular}{|c|c|c|c|c|c|c|c|c|c|c|}
\hline \multirow[b]{2}{*}{$\begin{array}{c}\text { Pap smear } \\
\text { diagnoses }\end{array}$} & \multicolumn{10}{|c|}{ Cervical biopsy diagnoses } \\
\hline & $\begin{array}{l}\text { Chronic } \\
\text { cervicitis }\end{array}$ & \begin{tabular}{|c|} 
Chronic \\
cervicitis with \\
squamous \\
metaplasia \\
\end{tabular} & $\begin{array}{c}\text { Papillary } \\
\text { endo-cervicitis }\end{array}$ & $\begin{array}{c}\text { CIN } \\
\text { I }\end{array}$ & CIN II & $\begin{array}{c}\text { CIN } \\
\text { III }\end{array}$ & CIS & SCC & Adenocarcinoma & Total \\
\hline ASCUS & 24 & - & - & 27 & 04 & - & - & - & - & 55 \\
\hline AGUS & - & - & 06 & - & - & - & - & - & 05 & 11 \\
\hline LSIL & 25 & 01 & - & 58 & 11 & - & - & - & - & 95 \\
\hline
\end{tabular}




\begin{tabular}{|l|c|c|c|c|c|c|c|c|c|c|}
\hline HSIL & - & - & - & - & 21 & 39 & 02 & 05 & 01 & 68 \\
\hline ASC-H & - & - & - & 01 & 11 & 10 & 04 & 02 & - & 28 \\
\hline SCC & - & - & - & - & - & - & 02 & 19 & - & 21 \\
\hline $\begin{array}{l}\text { Adeno } \\
\text { Carcinoma }\end{array}$ & - & - & - & - & - & - & - & - & 02 & 02 \\
\hline \multicolumn{1}{c}{ Total } & 49 & 01 & 06 & 86 & 47 & 49 & 08 & 26 & 08 & 280 \\
\hline
\end{tabular}

Table 5: Concordance and discordance cases between Pap smear and cervical biopsy diagnosis in different categories

\begin{tabular}{|l|c|c|c|}
\hline Pap smear diagnoses & Concordant cases & Discordant cases & Total cases \\
\hline ASCUS & 27 & 28 & 55 \\
\hline AGUS & 05 & 06 & 11 \\
\hline LSIL & 58 & 37 & 95 \\
\hline HSIL & 60 & 08 & 68 \\
\hline ASC-H & 21 & 07 & 28 \\
\hline SCC & 19 & 02 & 21 \\
\hline Adeno Carcinoma & 02 & 00 & 02 \\
\hline Total & $192(68.57 \%)$ & $88(31.43 \%)$ & 280 \\
\hline
\end{tabular}

Table 6: Diagnostic discrepancies between Pap smear and cervical biopsy diagnoses

\begin{tabular}{|l|c|c|}
\hline $\begin{array}{c}\text { No. of discrepant cases } \\
(\mathbf{n = 1 6 )}\end{array}$ & Diagnoses on Pap Smears & $\begin{array}{c}\text { Diagnoses on } \\
\text { Cervical biopsy }\end{array}$ \\
\hline 28 & ASCUS & $\begin{array}{c}\text { Chronic cervicitis: } 24 \text { cases } \\
\text { CIN II: } 04 \text { case }\end{array}$ \\
\hline 06 & AGUS & Papillary endocervicitis: 06 cases \\
\hline 37 & LSIL & Chronic cervicitis: 25 cases \\
Chronic cervicitis with squamous \\
& & metaplasia: 01 case \\
& & CIN II: 11 cases \\
\hline 08 & HSIL & CIS: 02 cases \\
& & SCC: 05 cases \\
& & Adenocarcinoma: 01 case \\
\hline 07 & ASC-H & CIN I: 01 cases \\
& & CIS: 04 cases \\
& & SCC: 02 cases \\
\hline 02 & SCC & CIS: 02 cases \\
\hline
\end{tabular}

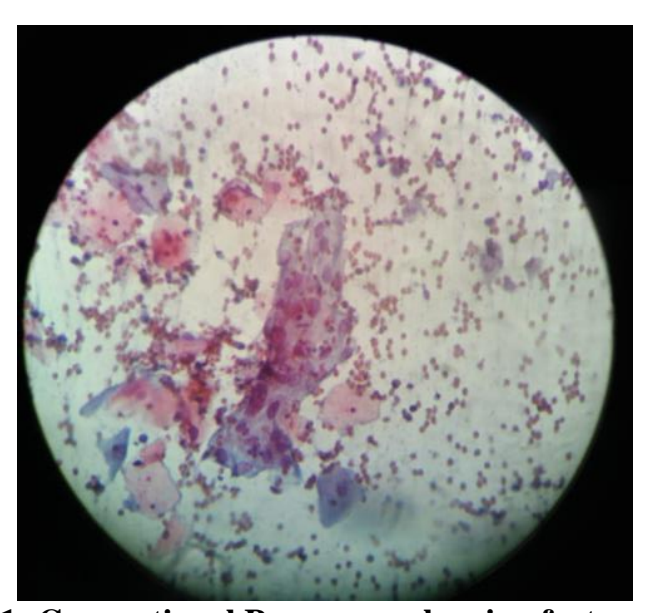

Fig. 1: Conventional Pap smear showing features of LSIL (Pap, 400X)

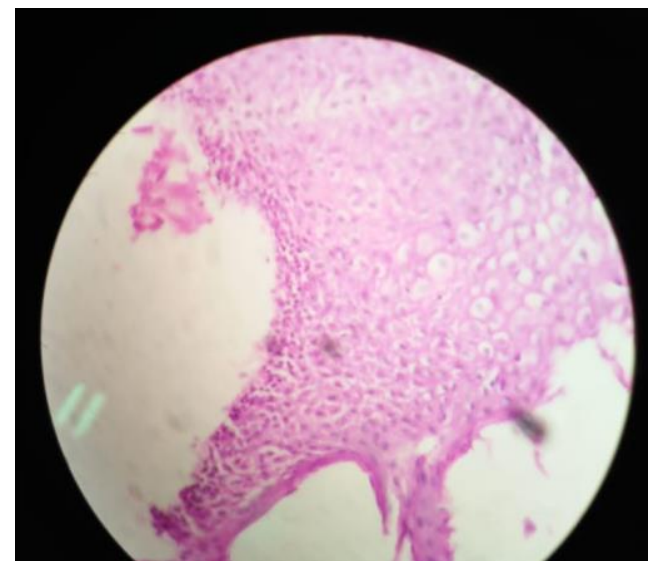

Fig. 2: Cervical biopsy of same case as Fig. 1 showing mild cervical dysplasia reported as CIN I $(\mathbf{H} \& \mathrm{E}, \mathbf{1 0 0 X})$ 


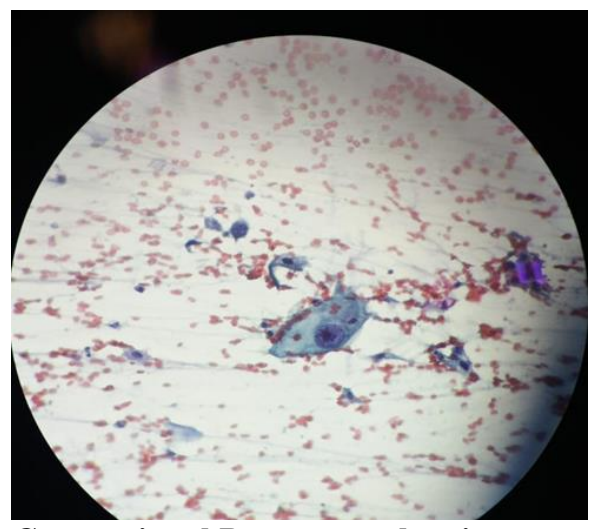

Fig. 3: Conventional Pap smear showing squamous carcinoma (Pap, 400X)

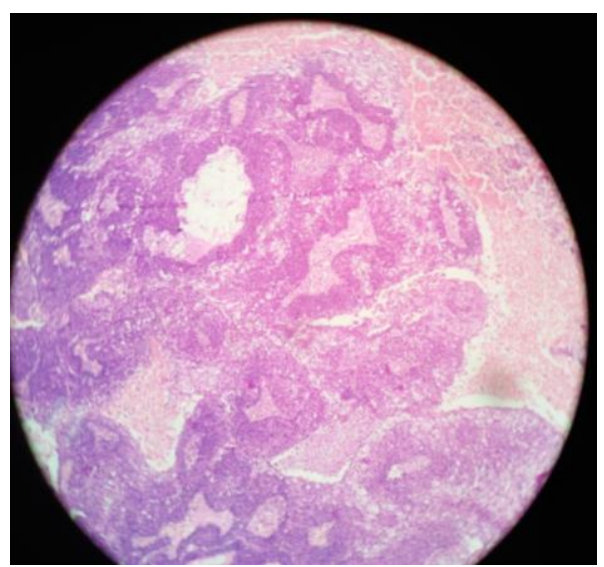

Fig. 4: Cervical biopsy showing invasive squamous cell carcinoma $(\mathrm{H} \& \mathrm{E}, 100 \mathrm{X})$

\section{Conclusion}

The study revealed a good correlation between cervical cytology and cervical biopsy Pap smear is an important screening tool for detection of precancerous and cancerous lesions of cervix. It is less invasive and simple procedure to perform on OPD basis. Also it is possible to issue reports within 24 hours of receipt of specimen. We also concluded that Pap smear is cost effective test for the early detection of precancerous and cancerous cervical lesions. However, it is necessary to perform cervical biopsy which is a gold standard, if any epithelial abnormalities are detected in cervical cytology for correlation and confirmation.

\section{References}

1. Narain A, Rao B, Prasad PR, Ganapathy H. Cyto histopathological Correlation of Pap Smear and Cervical Biopsy in Diagnosis of Cervical Lesions. SJAMS 2017;5(3C):873-880.

2. Klaes R, Friedrich T, Spitkovsky D, Ridder R, Rudy W, Petry U, Dallenbach-Hellweg G, Schmidt D, Von Knebel DM. Over expression of p16 as a specific marker for dysplastic and neoplastic epithelial cells of the cervix uteri. Int J Cancer 2001;92:276-84.

3. Ostor AG. Natural history of cervical intraepithelial neoplasia, a critical review. Int J Gynecol Pathol 1993; 12:186.
4. Nobbenhuis M, Walboomers J. Helmerhorst TJ, Rozendaal L, Remmink AJ, Risse EK, van der Linden HC, Voorhorst FJ, Kenemans P, Meijer CJ. Relation of human papillomavirus status to cervical lesions and consequences for cervical-cancer screening: a prospective study, Lancet 1999;354:20-25.

5. Cuzick J, Sasieni P, Davies P, Adams J, Normand C, Frater A, van Ballegooijen M, van den Akker-van Marle E. A systematic review of the role of human papilloma virus (HPV) testing within a cervical screening programme: summary and conclusions. Br J of Cancer 2000;83(5):561-565.

6. Munoz N and Bosch F. The causal link between HPV and cervical cancer and its implications for prevention of cervical cancer, Bulletin of the Pan-American Health Organization 1996;30:362-377.

7. Koutsky L, Holmes K, Critchlow C, Stevens C, Paavonen P, Beckmann A, De Roven T, Galloway D, Vennon D, Kiviat N. A cohort study of the risk of cervical intraepithelial neoplasia grade 2 or 3 in relation to papillomavirus infection, N Engl J Med 1992;327:12721278.

8. National Cancer Institute Workshop. The Bethesda System for reporting cervical/vaginal cytologic diagnoses: revised after the second National Cancer Institute Workshop, April 29-30, 1991. Acta Cytol 1993;37:115-124

9. Solomon D. The 1988 Bethesda system for reporting cervical/vaginal cytologic diagnoses. Developed and approved at the National Cancer Institute Workshop, Bethesda, Maryland, USA, December, 12-13. Acta Cytol 1989;33:567-574.

10. Kurman R, Malkasian D, Sedlis A, Solomon D. From Papanicolaou to Bethesda: the rationale for a new cervical cytologic classification. Obstet Gynecol 1991;77:779782.

11. Richart RM. Cervical intraepithelial neoplasia. Pathol Аппи 1973;8:301.

12. Channen W. The CIN saga - the biological and clinical significance of cervical intraepithelial neoplasia. Austr and N Zeal J Obstet Gynecol 1990;30:18-23.

13. Liaw KL, Glass AG, Manos MM, Greer CE, Scott DR, Sherman M, Burk RD, Kurman RJ, Wacholder S, Rush BB, Cadell DM, Lawler P, Tabor D, Schiffman $\mathrm{M}$. Detection of human papillomavirus DNA in cytologically normal women and subsequent cervical squamous intraepithelial lesions. $J$ the Nat Cancer Inst 1999;91:954-960.

14. Papanicolaou GN and Traut HF. The diagnostic value of vaginal smears in carcinoma of the uterus. Am J Obstet Gynecol 1941;42:193-206.

15. Vilos GA. The history of the Papanicolaou smear and the odyssey of George and Andromache Papanicolaou. Obstet Gynecol 1998;91:479.

16. DeMay RM. The Pap smear. In: DeMay RM (editor). The art and science of cytopathology. Chicago: American Society of Clinical Pathologists Press 1996:61-205.

17. Kudva R. Accuracy of Pap Smear Predictions: Cytohisologic Correlation. Am J of Clin Path 2015;144(2):

18. Dhakal R, Makaju R, Sharma S, Bhandari S, Shreshtha S, Bastakoti R. Correlation of Cervical Pap Smear with Biopsy in the Lesion of Cervix. Kathmandu Univ Med J 2016;55(3):254-7.

19. Ellenson LH, Pirog EC. The female genital tract In: Kumar V, Abbas AK, Fausto N, Aster JC. Robbins and Cotran Pathological basis of disease $8^{\text {th }}$ Edition Philadelphia: Saunders Elsevier 2012; 1005-1064. 
20. Bidus MA, Maxwell GL, Kulasingam S, Rose GS, Elkas JC, Chernofsky M, Myers ER. Cost-effectiveness analysis of liquid-based cytology and human papillomavirus testing in cervical cancer screening. Obstet Gynecol 2006;107:997-1005.

21. Parkin DM, Bray F, Ferlay J, Pisani P. Global cancer statistics, 2002. CA Cancer J Clin 2005;55:74-108.

22. Collins Y, Einstein M, Gostout BS, Mark H. Einstein B, Bobbie S. Gostout C, Thomas J, Herzog D, Massad S, Janet S, Rader F, Wright J. Cervical cancer prevention in the era of prophylactic vaccines: A preview for gynecologic oncologists. Gynecol Oncol 2006;102:552562.

23. Sankaranarayanan R, Budukh A, Rajkumar R. Effective screening programmes for cervical cancer in low- and middle-income developing countries. Bulletin of the WHO 2001;79:954-962.

24. Saha R, Thapa M. Correlation of cervical cytology with cervical histology. KUMJ. 2005;3(3), 222-224.

25. Bodal VK, Brar BK. Correlation of pap smear with histopathological findings in malignant and nonmalignant lesions of cervix. Glob J Med Res E Gynecol Obstet 2014;14:19-23.
26. Boyes DA, Nichols AM, Millner AM, Worth AJ. Recent results from the British Columbia screening program for cervical cancer. Amer J Obstet Gynaecol. 1977;128(6):692-3.

27. Pradhan B, Pradhan SB, Mital VP. Correlation of pap smear findings with clinical findings and cervical biopsy. KUMJ. 2007;5(4):461-467.

28. Chhabra Y, Behera BG, Khalkho J, Pati N. Cytomorphological study of cervical PAP smears for precancerous and cancerous lesions. J Cytol. 2003; 20:64-67.

29. Tamboli GD, Khatod LV. Accuracy of cytological findings in abnormal cervical smear by cyto- histological comparison. Journal of medical education and research. 2013;3(2):19-24. 